Tarazona, B. y Bernabé, M.: Rúbricas para evaluar la influencia de las TIC en el proceso de enseñanza/aprendizaje: estudio de caso en Educación Secundaria. Aula de Encuentro, n²1, volumen 1, pp. 85-104

\title{
Rúbricas para evaluar la influencia de las TIC en el proceso de enseñanza/aprendizaje: estudio de caso en Educación Secundaria
}

\section{Rubrics to assess the influence of ICT in the teaching/learning process: case study in Secondary Education}

\author{
Beatriz Tarazona Álvarez
}

María del Mar Bernabé Villodre

\begin{abstract}
Resumen
Utilizar las Tecnologías de la Información y de la Comunicación (TIC) en las aulas de Educación Secundaria contribuirá a un aprendizaje más efectivo para el adolescente en materias científico-técnicas; así como, la utilización de rúbricas para evaluar su enseñanza está considerado un instrumento eficaz para cuantificar dicho proceso. En este sentido, la experiencia de investigación-acción que aquí se presenta fue desarrollada en un instituto de Educación Secundaria de Valencia, en la materia de Biología-Geología. El objetivo de esta experiencia se centró en valorar la influencia de las TIC en el proceso de enseñanza/aprendizaje de esta asignatura, mediante rúbricas de evaluación. Se utilizaron dos metodologías opuestas (tradicional y aplicando TIC), tras lo cual, se procedió a la evaluación mediante las rúbricas validadas. Los resultados obtenidos mostraron la
\end{abstract}


considerable influencia positiva de las TIC en el aprendizaje de contenidos científicos en una etapa y con un estudiantado nacido en la era digital.

\title{
Palabras Clave
}

Rúbricas, enseñanza/aprendizaje, Tecnología de la Información y de la Comunicación, Educación Secundaria.

\begin{abstract}
Use of Information and Communication Technologies (ICT) in secondary education classrooms will contribute to a more effective learning for the adolescent in scientifictechnical subjects; as well as, the use of rubrics to evaluate their teaching is considered an effective instrument to quantify this process. In this sense, the research-action experience presented here was developed in a Secondary Education Institute in Valencia in the field of Biology-Geology. The objective of this experience was focused on assessing the influence of ICT in the teaching / learning process of this subject, through evaluation rubrics. Two opposing methodologies were used (traditional and applying ICT), after which the evaluation was carried out using the validated rubrics. The results obtained showed the considerable positive influence of ICT in the learning of scientific contents in a stage and with a student born in the digital age.
\end{abstract}

\section{Key Words}

Rubrics, teaching/learning, Information and Communication Technologies, Secondary Education.

\section{Introducción}

El rápido avance de la tecnología ha provocado la exigencia, por parte del alumnado, de una revisión metodológica, por parte del profesorado. Los docentes tienen que aprender a 
Tarazona, B. y Bernabé, M.: Rúbricas para evaluar la influencia de las TIC en el proceso de enseñanza/aprendizaje:

aprovechar en sus aulas el potencial como herramientas/instrumentos educativos de las denominadas Tecnologías de la Información y de la Comunicación (TIC, en adelante). El sector educativo no puede sustraerse a la realidad tecnológica y científica que le rodea, viéndose "obligado" a tratar de sacar el máximo rendimiento al uso de las TIC; y, en este sentido, no sólo como soporte del proceso educativo, sino como instrumento de apoyo hacia un cambio metodológico en el proceso de aprendizaje.

Los cambios tecnológicos que se vienen presenciando desde la última década del siglo XX y durante todo este ya más avanzado siglo XXI, han implicado un cambio radical y profundo en el paradigma metodológico de los centros educativos de Infantil, Primaria, Secundaria, Bachillerato e, incluso, de los centros de Enseñanzas Artísticas (Bernabé y Azorín, 2015). En la Educación Secundaria Obligatoria (ESO, en adelante), las TIC se han ido implementando con el consiguiente cambio en las estrategias didácticas. Cambios que han traído implícitos, a su vez, cambios en los roles que docente y discente deben desempeñar; además, han supuesto cambios en los objetivos, las metas formativas, las funciones, los materiales didácticos y, por tanto, en el sistema de evaluación (De Pablos y Marcelo, 2001).

Mucho se ha investigado sobre las ventajas de la utilización de las TIC frente a las de la metodología tradicional en Secundaria (García López y Romero, 2009). Entre esas ventajas señaladas por los autores, debe destacarse el aumento sustancial de la motivación y de la implicación del alumnado en el proceso de enseñanza/aprendizaje de las distintas asignaturas en ESO. En gran parte de los centros de Secundaria, se han venido incorporando con rapidez e intensidad las TIC, gracias a importantes inversiones por parte de cada Comunidad Autónoma. Ante esta situación, al profesorado no le queda sino mostrar una actitud positiva antes las TIC, porque éstas se han revelado como de uso positivo en numerosos estudios (López García y Morcillo Ortega, 2007). Estas mismas investigaciones han mostrado el interés, la motivación y la valoración de la necesidad de actualización profesional por parte del profesorado.

La incorporación efectiva de las TIC sólo será una realidad cuando suponga un cambio en las prácticas docentes. Es decir, que las tecnologías deben contribuir a que el alumnado se convierta en el principal actor de su proceso de aprendizaje. En esta dirección, giró esta investigación-acción desarrollada: ¿realmente, podían influir las TIC en el proceso de enseñanza/aprendizaje del alumnado de Biología-Geología de ESO? Y, para poder demostrar con mayor rigurosidad el proceso seguido, se realizaron unas rúbricas de evaluación.

El proceso de Convergencia Europea no sólo trajo consigo una renovación en la comprensión de la estructura de los Grados universitarios, sino también en las estrategias docentes y en los sistemas de evaluación, cambios que debían iniciarse en etapas formativas anteriores. En este sentido, para las diferentes etapas educativas, el objetivo ya no es sólo la adquisición de conocimientos sino el desarrollo de capacidades; y, esto sólo será posible si las metodologías docentes dan paso a actividades para facilitar la adquisición de determinadas competencias (García Irles, Sempere, Marco y De la Sen, 2011).

Es en este marco donde las rúbricas de evaluación pueden convertirse en una eficaz herramienta para profesorado y alumnado (Dodge, 1997; Villalustre y del Moral, 2010). Son instrumentos de medición con criterios establecidos por niveles, mediante la 
disposición de escalas que permiten determinar la calidad en la ejecución de determinadas tareas por parte del estudiantado (Vera, 2008). De modo que, posibilitan la especificación de las competencias que deben alcanzarse en el proceso de enseñanza/aprendizaje y los criterios que regularán el mismo; así, el alumnado podrá regular su propio aprendizaje y participar del sistema de evaluación más activamente.

Heywood (2000, citado en Sáiz, Carbonero y Román, 2012, p. 1065) considera que las principales características de las rúbricas son:

- Presentan una lista de criterios destinados a evaluar las metas que implican las tareas o problemas propuestos en el aula.

- Presentan una gradación en niveles de ejecución de las tareas, en orden de análisis cuantitativo y cualitativo.

- $\quad$ El alumnado puede comparar su trabajo durante todo el proceso de aprendizaje.

La introducción de las rúbricas en la evaluación atiende a tres momentos por los que pasa el alumnado (Chow, Ko, Li y Zhou, 2012):

- Explorar un tema y hallar la información relevante: esto supone que el alumnado desarrolla su curiosidad.

- Buscar conocimientos adicionales: supone la incentiva de la iniciativa e independencia del alumnado).

- Revisar la experiencia de aprendizaje, con una perspectiva más amplia: así, el alumnado aprenderá para la transferencia del conocimiento y la reflexión.

Las rúbricas deben presentarse al alumnado desde el inicio del proceso de enseñanza/aprendizaje, para facilitarles la planificación de sus metas, así como la información de aquello que se espera de ellos (Sáiz, Carbonero y Román, 2012).

El valor de las rúbricas a la hora de evaluar resultados de aprendizaje se ha revelado como especialmente eficaz en numerosos estudios (Santana, 2013; Valverde y Ciudad, 2014; Paredes, Tarazona, Zamora y Gandía, 2014). Gracias a su utilización, la evaluación multiplica su objetividad y se vuelve más completa en cuanto a las competencias del alumnado. No obstante, el hecho de utilizarlas no implica garantía de éxito en la consecución de los aprendizajes por parte del alumnado; puesto que su efectividad depende del diseño de éstas (Panadero et al., 2012, citado en Sáiz, Carbonero y Román, 2012, p. 1065). La metodología de rúbricas es un procedimiento de gran ayuda a la hora de realizar una evaluación continua, ya que permite al alumnado ser más consciente de sus propias actuaciones y evaluarlas facilitando su proceso de enseñanza/aprendizaje. Las rúbricas podrían quedar integradas en los estudios para reducir al mínimo la ambigüedad y la incertidumbre en la interpretación de las respuestas del alumnado. Por tanto, se evidencia la necesidad de introducir su uso en la evaluación de una forma clara, con la intencionalidad de que el alumnado sea consciente de lo que se espera de ellos y, así, puedan planificar su aprendizaje.

La propuesta de investigación-acción que se presenta, se realizó con dos temas, "La formación de un nuevo ser" y "Reproducción y salud", de la Unidad Didáctica "La reproducción humana” dentro de la asignatura de Biología-Geología de $3^{\circ}$ de ESO. 


\section{Método}

Seguidamente, se comentan los distintos momentos de la investigación realizada.

\subsection{Objetivos}

Interlineado sencillo. El objetivo principal de la investigación-acción desarrollada consistió en, a partir de la elaboración y aplicación de una Unidad Didáctica con dos metodologías distintas (tradicional y con TIC), comparar los resultados de ambos procesos mediante la utilización de rúbricas de evaluación y test de conocimientos.

A nivel específico, se persiguieron los siguientes objetivos:

- Posibilitar métodos alternativos de enseñanza/aprendizaje de las Ciencias, alejados de la "tradición".

- Analizar la efectividad de una nueva metodología en el proceso de aprendizaje, antes y después de las clases, mediante la evaluación del alumnado con rúbricas.

- Comprobar la fiabilidad de la escala de evaluación por rúbricas.

- Contrastar los resultados obtenidos entre los dos grupos para señalar posibles diferencias significativas.

\subsection{Población y muestra}

Interlineado sencillo. Se trabajó con una muestra de 36 estudiantes, repartidos en dos grupos de tercer curso de Educación Secundaria Obligatoria (véase Tabla 1):

\begin{tabular}{lccc}
\hline & \multicolumn{3}{c}{ Grupo } \\
\cline { 2 - 4 } & Total & A & B \\
\hline $\mathrm{n}$ & 34 & 17 & 17 \\
Media & 14,4 & 14,3 & 14,4 \\
Desviación & 0,7 & 0,6 & 0,8 \\
típica & & & \\
Mínimo & 14,0 & 14,0 & 14,0 \\
Máximo & 16,0 & 16,0 & 16,0 \\
\hline
\end{tabular}

Tabla 1. Número total de estudiantes por grupo y media, desviación típica, mínimo y máximo de edad

El Grupo A estaba compuesto por 17 sujetos, entre ellos, 11 eran mujeres y 6 hombres, con edades medias de 14 y 14-17 años, respectivamente. Y, el Grupo B se componía de 19 sujetos, 10 mujeres con una media de 14,44 años, y 9 hombres (media de edad de 14,4 años) (véase Tabla 2). Ambos grupos pertenecían a un centro concertado de la ciudad de Valencia:

\section{Grupo}




\begin{tabular}{lcccccc} 
& \multicolumn{2}{c}{ Total } & \multicolumn{3}{c}{$\mathbf{A}$} & \multicolumn{1}{c}{ B } \\
\cline { 2 - 7 } & $\mathbf{n}$ & $\mathbf{0}$ & $\mathbf{n}$ & $\mathbf{\%}$ & $\mathbf{n}$ & $\mathbf{\%}$ \\
\hline Total & 34 & 100,0 & 17 & 100,0 & 17 & 100,0 \\
Hombres & 14 & 41,2 & 6 & 35,3 & 8 & 47,1 \\
Mujeres & 20 & 58,8 & 11 & 64,7 & 9 & 52,9 \\
\hline
\end{tabular}

Tabla 2. Distribución de estudiantes por sexo

En el Grupo B, se contaba con dos estudiantes con necesidades educativas especiales; mientras que, en el Grupo A, no. Estos estudiantes no pudieron seguir el desarrollo de la Unidad Didáctica, tal como se plantea en epígrafes siguientes; de modo que, se realizaron ciertas adaptaciones curriculares para que pudiesen participar en la mayor medida posible, en el desarrollo grupal de la actividad.

El alumnado de esta edad vive un momento crucial en su desarrollo cognitivo y socioafectivo. A nivel cognitivo, abandona el estadio de operaciones concretas para caminar hacia las operaciones formales que, de acuerdo con Piaget (1985), se caracteriza por tres elementos fundamentales: la realidad es concebida como un subconjunto de lo posible, el carácter hipotético-deductivo de las reflexiones, y el carácter proposicional del pensamiento. Gracias a esto, cuenta con nuevas "puertas" en las posibilidades de razonamiento y aprendizaje, en las que el docente debe trabajar con las herramientas adecuadas para garantizar una evolución acorde con sus capacidades.

La población comprendida en este margen de edad sufre una crisis de oposición sociofamiliar, como consecuencia de la necesidad individual de autoafirmación, de autonomía e independencia intelectual y emocional. Se presencia el desarrollo de un lenguaje propio, la formación de grupos sociales y relaciones afectivas con otras personas, más allá de su entorno familiar. Y, a todo esto, vienen a sumarse complejos, inseguridades y problemas de autoestima que influyen el éxito o fracaso del proceso educativo.

\subsection{Instrumento}

Interlineado sencillo. Se elaboró una prueba objetiva de conocimientos tipo test, constituida por cinco preguntas con tres opciones de respuesta, utilizada pre y post experiencia: 5 ítems con una puntuación máxima de 10 (véanse Tablas 3 y 4):

\begin{tabular}{llcc}
\hline Preguntas & & Respuestas & C \\
\cline { 2 - 4 } & A & B & Dos óvulos \\
fecundació & Un & Dos óvulo y un & des \\
$\mathrm{n}$ es la & espermatozoid & \\
unión de... & e & & El feto \\
$2 . \quad$ El cigoto & El embrión & \\
resultado & & & \\
inmediato & & & \\
de la & & & \\
fecundació & & &
\end{tabular}


n es...

\begin{tabular}{|c|c|c|c|}
\hline $\begin{array}{l}3 . \quad \text { La } \\
\text { fecundació } \\
n \quad \text { ocurre } \\
\text { en... }\end{array}$ & El útero & $\begin{array}{l}\text { Las trompas } \\
\text { de Falopio }\end{array}$ & El óvulo \\
\hline $\begin{array}{l}4 . \quad \text { La } \\
\text { placenta y } \\
\text { el amnios } \\
\text { sirven } \\
\text { para... }\end{array}$ & $\begin{array}{l}\text { Proteger } \\
\text { embrión }\end{array}$ & $\begin{array}{l}\text { Nutrir } \\
\text { embrión }\end{array}$ & $\begin{array}{l}\text { Proteger y nutrir } \\
\text { al embrión }\end{array}$ \\
\hline $\begin{array}{l}\text { 5. Las } 3 \\
\text { fases del } \\
\text { parto son, } \\
\text { por }\end{array}$ & $\begin{array}{l}\text { Dilatación, } \\
\text { expulsión y } \\
\text { alumbramiento }\end{array}$ & $\begin{array}{l}\text { Expulsión, } \\
\text { dilatación y } \\
\text { alumbramient } \\
\text { o }\end{array}$ & $\begin{array}{l}\text { Alumbramiento, } \\
\text { dilatación y } \\
\text { expulsión }\end{array}$ \\
\hline
\end{tabular}

Tabla 3. Test de conocimientos previos. Tema 5. La formación de un nuevo ser

\begin{tabular}{|c|c|c|c|}
\hline \multirow[t]{2}{*}{ Preguntas } & \multicolumn{3}{|c|}{ Respuestas } \\
\hline & $\mathbf{A}$ & B & C \\
\hline $\begin{array}{l}1 . \quad \text { Las } \\
\text { enfermedade }\end{array}$ & $\begin{array}{l}\text { Hongos } \quad y \\
\text { bacterias }\end{array}$ & $\begin{array}{l}\text { Hongos, } \\
\text { bacterias y }\end{array}$ & $\begin{array}{l}\text { Bacterias y } \\
\text { virus }\end{array}$ \\
\hline $\begin{array}{l}\text { s de } \\
\text { transmisión } \\
\text { sexual (ETS) } \\
\text { están } \\
\text { provocadas } \\
\text { por... }\end{array}$ & & virus & \\
\hline $\begin{array}{l}\text { 2. EI SIDA es } \\
\text { una } \\
\text { enfermedad } \\
\text { causada }\end{array}$ & Virus VIH & Bacteria VIH & Virus VCD \\
\hline $\begin{array}{l}\text { por... } \\
\text { 3. El VIH se } \\
\text { transmite a } \\
\text { través de... }\end{array}$ & $\begin{array}{l}\text { La sangre, el } \\
\text { semen, las } \\
\text { secreciones } \\
\text { vaginales y la } \\
\text { leche } \\
\text { materna }\end{array}$ & $\begin{array}{l}\text { La sangre, el } \\
\text { semen y las } \\
\text { secreciones } \\
\text { vaginales }\end{array}$ & $\begin{array}{l}\text { La leche } \\
\text { materna }\end{array}$ \\
\hline $\begin{array}{l}4 . \quad \text { La } \\
\text { amniocentesi }\end{array}$ & $\begin{array}{l}\text { Enfermeda } \\
\text { des en la }\end{array}$ & $\begin{array}{l}\text { Enfermedades } \\
\text { en la madre y }\end{array}$ & $\begin{array}{l}\text { Enfermedade } \\
\text { s en el feto }\end{array}$ \\
\hline $\begin{array}{l}\text { durante el } \\
\text { embarazo... }\end{array}$ & & & \\
\hline $\begin{array}{l}\text { 5. El mejor } \\
\text { tratamiento } \\
\text { para las ETS } \\
\text { es... }\end{array}$ & La prevención & Medicamentos & $\begin{array}{l}\text { No hay } \\
\text { tratamiento }\end{array}$ \\
\hline
\end{tabular}

Tabla 4. Test de conocimientos previos. Tema 7. Reproducción y salud 
La escala de evaluación por rúbricas se utilizó antes y después de la experiencia práctica con TIC llevada a cabo (véanse Tablas 5 y 6). Dicha escala constaba de un total de nueve ítems, centrados en analizar los conocimientos del alumnado en la Unidad Temática comentada en epígrafes siguientes. Las posibilidades de respuesta eran: 1 (No lo sé), 2 (Tengo alguna vaga idea), 3 (Tengo una idea aproximada), 4 (Lo sé bien) y 5 (Lo sé muy bien):

\begin{tabular}{|c|c|c|c|c|c|}
\hline \multirow[t]{2}{*}{ Nombre: } & \multicolumn{3}{|c|}{ Apellidos: } & \multicolumn{2}{|c|}{ Edad: } \\
\hline & 1 & 2 & 3 & 4 & 5 \\
\hline \multicolumn{6}{|l|}{ Conozco el concepto de fecundación } \\
\hline \multicolumn{6}{|l|}{ Sé dónde se produce la fecundación } \\
\hline \multicolumn{6}{|l|}{ Conozco el concepto de cigoto } \\
\hline \multicolumn{6}{|l|}{ Sé qué camino sigue el cigoto } \\
\hline \multicolumn{6}{|l|}{ Conozco el concepto de placenta } \\
\hline \multicolumn{6}{|l|}{ Conozco el concepto de amnios } \\
\hline \multicolumn{6}{|l|}{ Conozco cómo se desarrolla el embrión } \\
\hline \multicolumn{6}{|l|}{ Conozco el concepto de parto } \\
\hline Sé qué tres fases comprende el parto & & & & & \\
\hline
\end{tabular}

Tabla 5. Hoja de registro de la evaluación de rúbricas. Tema 5. La formación de un nuevo ser

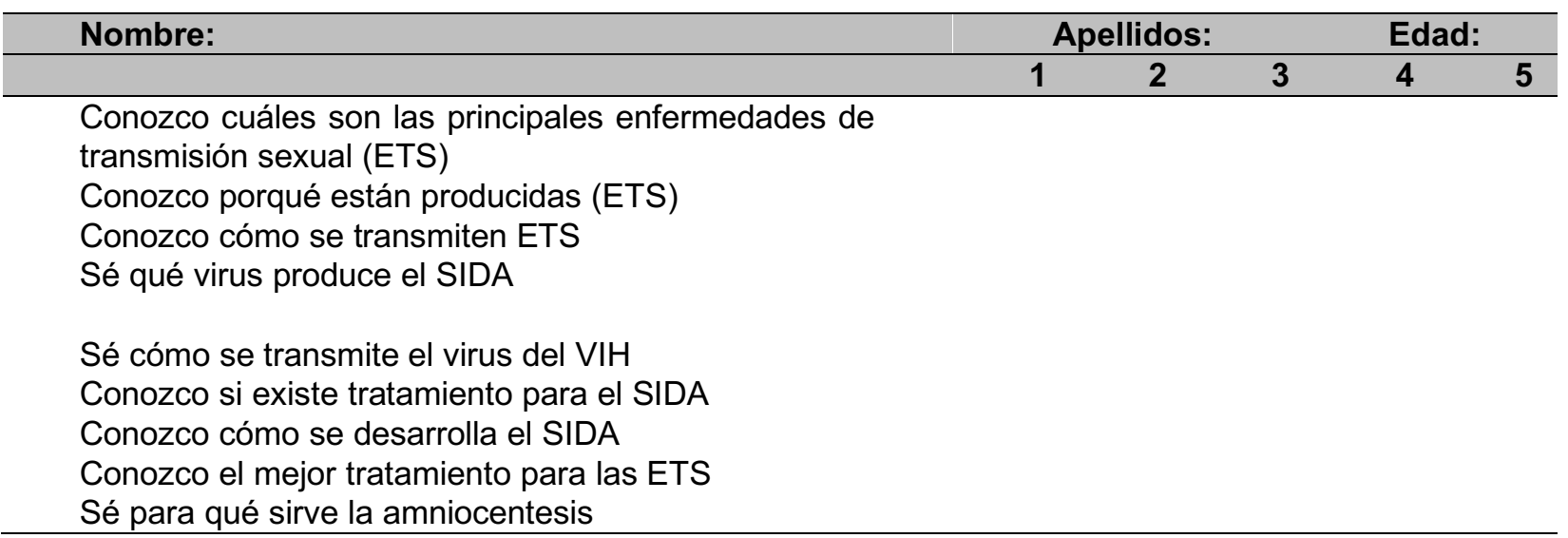

Tabla 6. Hoja de registro de la evaluación de rúbricas. Tema 7. Reproducción y salud

Las puntuaciones máximas por subtemas de conocimiento fueron:

- Tema 5: "La formación de un nuevo ser": 9 ítems, puntuación máxima 45.

- Tema 7: "Reproducción y salud”: 9 ítems, puntuación máxima 45.

La fiabilidad total del instrumento (consistencia interna) fue de:

- Tema 5: $\square=0,71$.

- Tema 7: $\square=0,72$. 


\subsection{Procedimiento de recogida y análisis de datos}

El plan de trabajo desarrollado fue el siguiente. En primer lugar, se recogió información sobre la temática que debía trabajarse y se analizó tanto la programación de la didáctica como las unidades propuestas en el libro de texto. Así, se pudo diseñar parte de una Unidad Didáctica donde se programaron actividades con una metodología tradicional y otras con TIC. En segundo lugar, se procedió a la aplicación y evaluación de los dos temas mediante una prueba objetiva y unas rúbricas de evaluación pre y post intervención. Después, se compararon las dos metodologías aplicadas y, finalmente, se compararon los resultados de los dos grupos de estudiantes.

Las actividades desarrolladas partieron del bloque de contenidos "Las personas y la salud", donde la Unidad Didáctica "La reproducción humana" permitió trabajar los elementos expuestos en la Tabla 7. De ésta, se explicaron dos partes ("La formación de un nuevo ser" y "Reproducción y salud") a cada uno de los dos grupos de forma diferente (tradicional, uno, y el otro, con TIC):

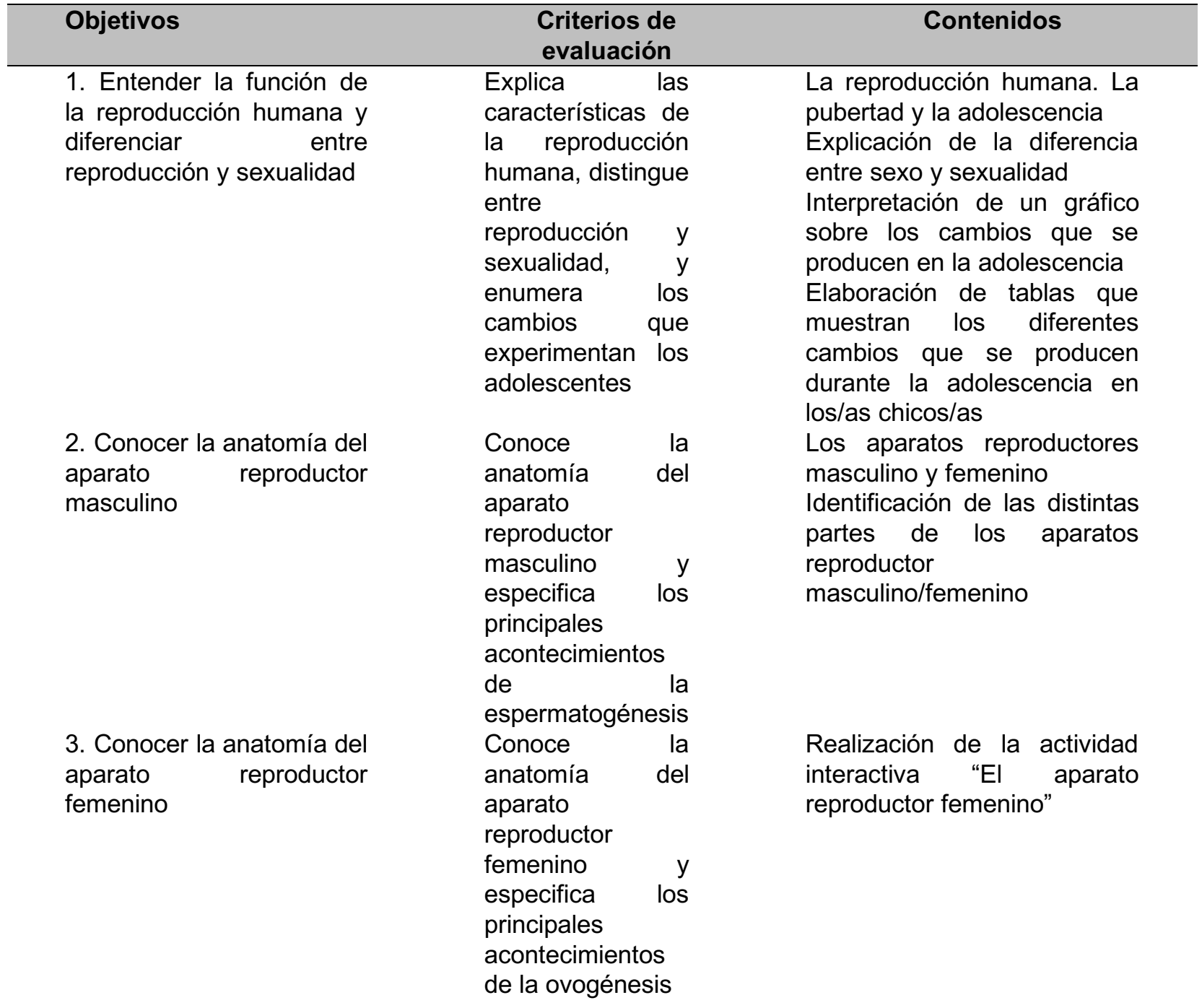


4. Conocer la fisiología del aparato reproductor femenino

5. Describir la fecundación y el desarrollo embrionario

6. Comprender los problemas relacionados con la fertilidad y las enfermedades de transmisión sexual
Diferencia entre ciclo ovárico y ciclo uterino, y cita las hormonas que regulan el ciclo reproductor

Define fecundación, describe el camino que recorre el embrión hasta el útero e identifica los principales acontecimientos que se producen durante el desarrollo embrionario

\begin{tabular}{|c|}
\hline $\begin{array}{l}\text { Valora } \\
\text { técnicas } \\
\text { reproducción } \\
\text { asistida y } \\
\text { métodos } \\
\text { control de } \\
\text { fertilidad, } \\
\text { identifica } \\
\text { principales } \\
\text { enfermedades } \\
\text { transmisión } \\
\text { sexual y }\end{array}$ \\
\hline
\end{tabular}

El ciclo ovárico y la ovulación. El ciclo del útero y la menstruación

Interpretación de esquemas sobre el ciclo menstrual y el ciclo ovárico

Análisis de esquemas que muestran la regulación hormonal de los ciclos ováricos y del útero

Los espermatozoides y su formación. Los óvulos y su formación

Dibujo de un espermatozoide y un óvulo para indicar las partes

Dibujo de la espermatogénesis y de la ovogénesis

La fecundación. El embarazo. El parto Localización sobre un dibujo de los procesos de fecundación e implantación Identificación en dibujos de las fases del parto Interpretación de gráficos sobre las contracciones uterinas

Elaboración de una tabla que muestre los cambios que experimenta el feto durante el embarazo

Realización de la actividad interactiva "Las fases del parto"

Valoración de la importancia de la amniocentesis para conocer el desarrollo del feto Realización de la actividad interactiva "Órganos, gametos y hormonas sexuales"

Métodos anticonceptivos. La reproducción asistida

Interpretación de datos sobre el grado de seguridad de diferentes métodos anticonceptivos Análisis de esquemas sobre la fecundación in vitro 


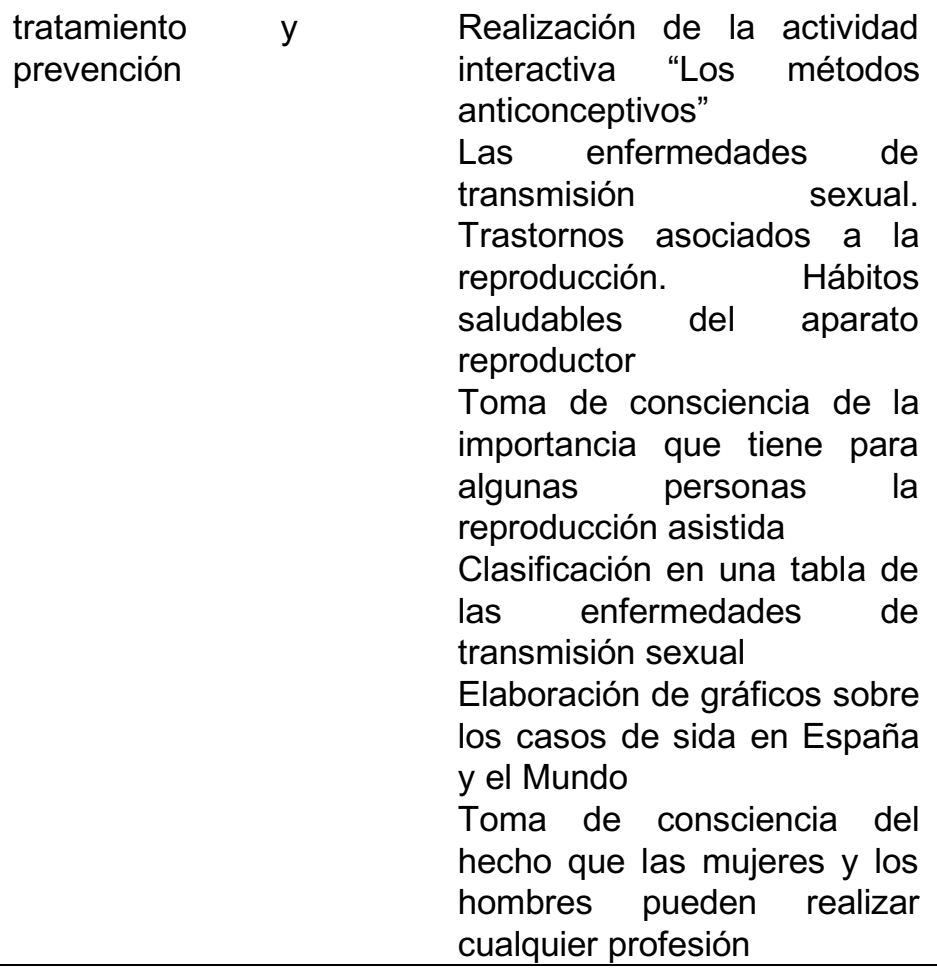

Tabla 7. Unidad Didáctica: La reproducción humana

Las clases se prepararon en función de las dos metodologías: la tradicional partió del uso del libro de texto como principal herramienta del acto didáctico; y, la metodología con ayuda de TIC, en este caso, un elemento tan sencillo como proyecciones de PowerPoint y búsquedas en Internet.

El test de conocimientos previos permitió ver los conceptos asimilados por el alumnado, previo a la intervención educativa. Al finalizar ésta, volvió a aplicarse para ver cómo había sido más efectivo el aprendizaje, si con una u otra metodología. Aquí, las rúbricas, previas y posteriores, permitieron una mayor objetividad y rigurosidad en los datos obtenidos durante esta investigación-acción.

La metodología tradicional utilizada partió de la denominada clase magistral: se realizó una presentación de los contenidos, siguiendo el discurso establecido en el libro de texto, con el apoyo puntual de la pizarra tradicional. Se buscó cierta interacción docentediscente para comprobar el grado de comprensión de los contenidos expuestos, y para reforzar aquellos aspectos que no les hubiesen resultado comprensibles. Se combinó la exposición teórica con actividades prácticas del libro de texto e invitaciones al diálogo.

Durante las clases con el grupo de metodología tradicional, se buscó un efecto muy visual, con gran número de imágenes conocidas y/o del entorno, para hacer más cercanos los contenidos explicados. De esta manera, gracias a la interacción profesorado-alumnado, el primero podría hacerse una idea sobre el grado de comprensión del segundo: permitiría que conectasen conocimientos previos y reforzar aquellos cuya comprensión les ofreciese problemas. 
Tarazona, B. y Bernabé, M.: Rúbricas para evaluar la influencia de las TIC en el proceso de enseñanza/aprendizaje:

La metodología tradicional permitió la combinación entre teoría y práctica e invitaciones al diálogo, aunque las TIC no estuviesen presentes se pudo garantizar cierta interacción y respuesta por parte del alumnado.

En cuanto al grupo con el que se trabajó desde una metodología con TIC, ésta partió de la comprensión del alumnado como responsable primero de sus aprendizajes. Esto fue posible porque se pretendía centrar el proceso en actividades de búsqueda de información y posterior consenso para crear sus propios materiales de estudio. La intención primera fue el trabajo autónomo del alumnado, el denominado autoaprendizaje en el que el profesorado actúa como guía y en el que la implicación del estudiantado es mayor que en la metodología tradicional. Sólo así, el alumnado podrá desarrollar una serie de competencias básicas que la metodología tradicional no posibilita: estaríamos ante una construcción de sus propios aprendizajes (aprender a aprender), un trabajo del sentido de la iniciativa y espíritu emprendedor, al tiempo que se trabajaría la competencia digital.

Más allá de las técnicas de estudio, debe enseñarse al estudiantado a aprender, a buscar información nueva de utilidad, a utilizar dicha información y evaluar su importancia para la resolución de problemas. La metodología propuesta con tecnologías les motiva, facilita la interacción grupal, al tiempo que sus destrezas comunicativas y el conocimiento de sí mismos.

Unas mínimas indicaciones durante el desarrollo de la Unidad Didáctica con el grupo TIC, permitió el desarrollo de forma individual de parte de los contenidos haciendo un resumen del punto del tema a tratar. Por supuesto que usaron el libro de texto, pero el acceso a Internet multiplicó la información (de interés) y la adición de imágenes a sus trabajos. Aunque, para las explicaciones docentes no se recurrió al libro de texto, sino a presentaciones PowerPoint y la visualización de diferentes vídeos relacionados con los contenidos expuestos en la Tabla 7. Todo esto culminó con algunos de los trabajos realizados en sus casas, para hacer una puesta en común y ofrecerles feedback de todo el proceso seguido.

Trabajando con las dos metodologías se ha perseguido partir del nivel de desarrollo del alumnado para construir, desde ahí, otros aprendizajes que favorezcan y mejoren su nivel de desarrollo. Se dio prioridad a los aspectos procedimentales y actitudinales sobre los conceptuales, siempre tratando de conectar estos últimos con los intereses y necesidades del alumnado.

Los momentos de reflexión personal sobre los distintos momentos del proceso de aprendizaje y la elaboración de conclusiones al respecto, fueron parte importante de esta investigación-acción. Se perseguía que el discente pudiese analizar su progreso respecto a sus conocimientos previos, detectados gracias a la realización de los test previos. Y, todo esto gracias al hecho de que se propiciaron oportunidades educativas para poner en práctica los nuevos conocimientos trabajados, como forma también de comprobar intereses y utilidad de lo aprendido.

Las clases con TIC no eran unidireccionales ni monográficas, potenciándose la investigación e indagación por parte del alumnado, gracias a las búsquedas en Internet. 


\section{Discusión de resultados}

Se han estimado modelos de ecuaciones de estimación generalizada (EEG) para realizar el análisis de la evolución de las distintas variables de respuesta a lo largo del tiempo de la investigación-acción realizada (medidas repetidas), teniendo en cuenta el método de aprendizaje aplicado al sujeto (grupo TIC-grupo tradicional).

Se evaluaron los cambios en el tiempo acotado, según el método y en la interacción entre ambos. El efecto interacción es el fundamental para concluir sobre la diferencia de efectividad de los métodos empleados. La elección de esta técnica estadística partió del carácter ordinal o no normal de las variables de respuesta nota del test y la media de las rúbricas, respectivamente; además, de la correlación propia de las mediciones repetidas llevadas a cabo.

Los efectos principales e interacción se evaluaron mediante test estadístico Chi cuadrado. $Y$, la fiabilidad o consistencia interna de las preguntas de cada tema se evaluó mediante el coeficiente alfa de Cronbach. En cuanto al nivel de significatividad empleado en el análisis, ha sido el $5 \%(\alpha=0,05)$.

Para un modelo estadístico como el descrito y aplicado a la muestra de 34 estudiantes, con un nivel de significatividad del $5 \%$ y considerando un tamaño del efecto a detectar de 0,25 (medio), la potencia alcanzada es 0,94 para el contraste de los efectos intra-sujetos.

Centrándonos en la variable "Test de conocimientos", los efectos del método y el tiempo en la nota del examen del test de conocimientos aplicado antes y después de cada una de las clases puede verse en el Gráfico 1, que muestra la media y la desviación típica (DT) de la nota obtenida en cada método (tradicional-TIC) antes y después de la investigación-acción realizada:

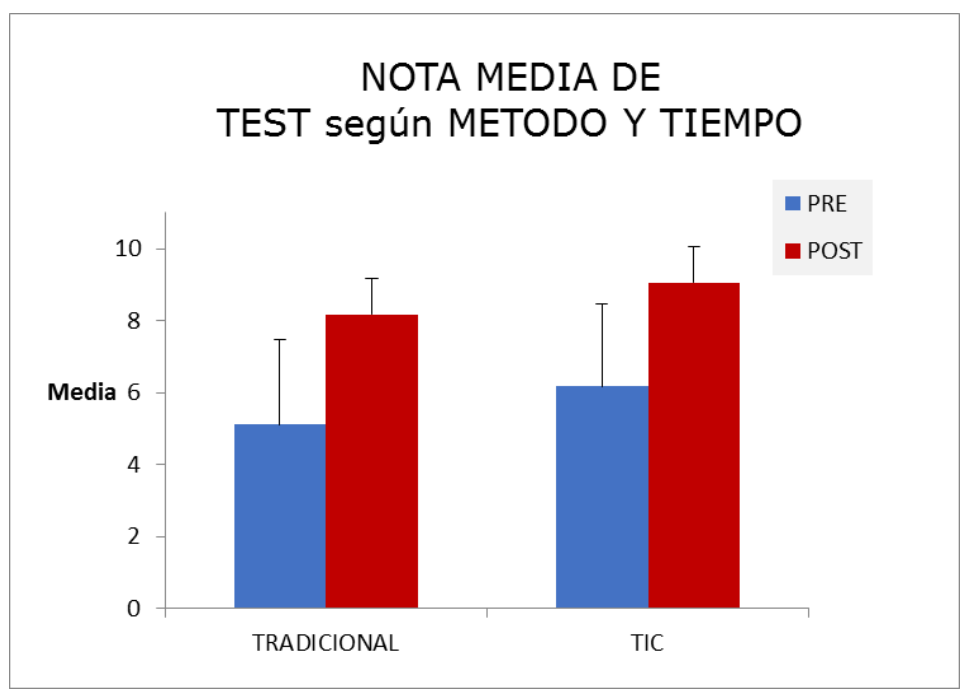

Gráfico 1. Nota media del test de conocimientos pre y post con ambas metodologías

La impresión transmitida por el Gráfico 1 indica que los dos métodos han conseguido una nota media que aumenta con el tiempo, no pudiendo considerarse que haya un método que aumente la nota media final de forma significativamente superior al otro. Este dato, 
sugerido a nivel descriptivo, ha sido contrastado con el modelo analítico adecuado (EEG), obteniéndose los siguientes resultados:

- Diferencias significativas con el factor "Tiempo" ( $p$-valor<0,001): tanto con la metodología tradicional como con la metodología con TIC, las calificaciones fueron superiores después de impartir el temario.

- $\quad$ Diferencias por método ( $p$-valor<0,001): con TIC se observan unas calificaciones superiores que con la tradicional en ambos grupos (Gráficos 2 y 3 ).

- No hay interacción entre "Método"-"Tiempo": no se aprende más con un método que con otro ( $p$-valor 0,314 ). Con TIC, se llega a unos resultados superiores, pero también hay que tener en cuenta que se parte de mejores notas que la tradicional. Por tanto, no puede afirmarse que la metodología TIC permita obtener mejores resultados en ninguno de los grupos trabajados.

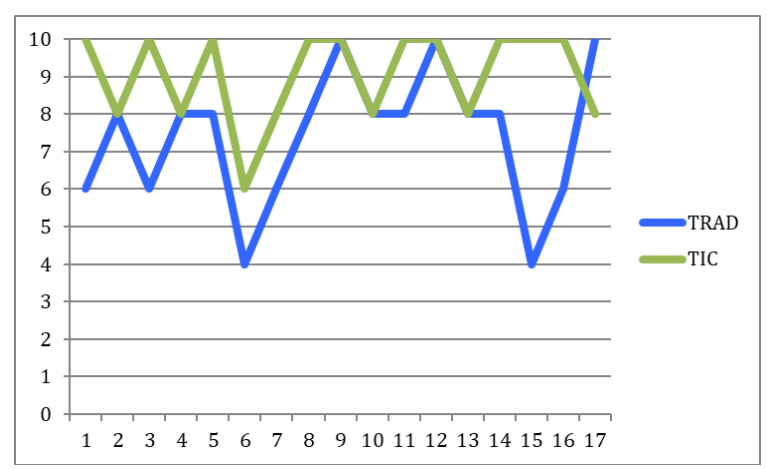

Gráfico 2. Notas finales del test de conocimientos previos del Grupo A

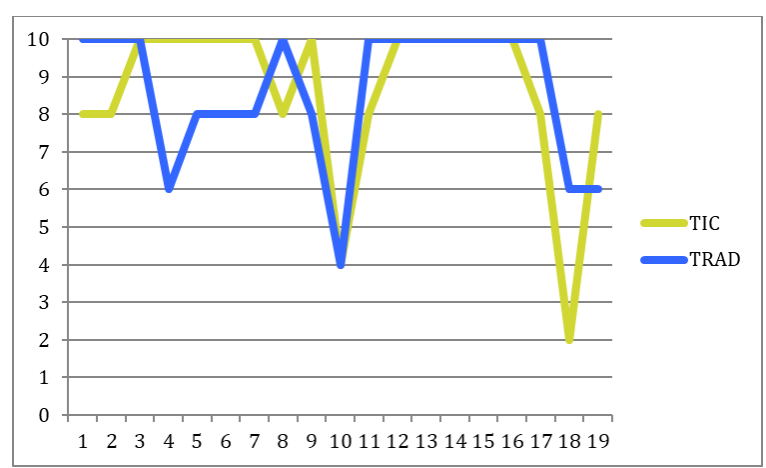

Gráfico 3. Notas finales del test de conocimientos previos del Grupo B

No obstante, la ausencia de diferencias estadísticamente significativas, pueden observarse en la Tabla 8 las medias de los distintos test realizados por el alumnado antes y después de la investigación-acción desarrollada por ambos grupos con los métodos propuestos:

\begin{tabular}{llllcr}
\hline & & \multicolumn{3}{c}{ Grupo } \\
\cline { 3 - 5 } & & & Total & A & B \\
\hline TEST & ANTES & $\mathrm{n}$ & 34 & 17 & 17 \\
TIC & \multirow{2}{*}{ Media } & 6,18 & 7,06 & 5,29
\end{tabular}




\begin{tabular}{|c|c|c|c|c|}
\hline & $\begin{array}{l}\text { Desviación } \\
\text { típica }\end{array}$ & 2,28 & 1,89 & 2,34 \\
\hline & Mínimo & 2,0 & 4,0 & 2,0 \\
\hline & Máximo & 10,0 & 10,0 & 10,0 \\
\hline & Mediana & 6,00 & 8,00 & 4,00 \\
\hline \multirow{6}{*}{$\begin{array}{l}\text { TEST ANTES } \\
\text { TRADICIONAL }\end{array}$} & $\mathrm{N}$ & 34 & 17 & 17 \\
\hline & Media & 5,12 & 3,76 & 6,47 \\
\hline & $\begin{array}{l}\text { Desviación } \\
\text { típica }\end{array}$ & 2,37 & 1,56 & 2,29 \\
\hline & Mínimo & 2,0 & 2,0 & 4,0 \\
\hline & Máximo & 10,00 & 6,00 & 10,00 \\
\hline & Mediana & 4,00 & 4,00 & 6,00 \\
\hline \multirow{6}{*}{$\begin{array}{l}\text { TEST } \\
\text { DESPUÉS TIC }\end{array}$} & $\mathrm{n}$ & 34 & 17 & 17 \\
\hline & Media & 9,06 & 9,06 & 9,06 \\
\hline & $\begin{array}{l}\text { Desviación } \\
\text { típica }\end{array}$ & 1,41 & 1,25 & 1,60 \\
\hline & Mínimo & 4,0 & 6,0 & 4,0 \\
\hline & Máximo & 10,0 & 10,0 & 10,0 \\
\hline & Mediana & 10,00 & 10,00 & 10,00 \\
\hline \multirow{6}{*}{$\begin{array}{l}\text { TEST } \\
\text { DESPUÉS } \\
\text { TRADICIONAL }\end{array}$} & $\mathrm{N}$ & 34 & 17 & 17 \\
\hline & Media & 8,18 & 7,41 & 8,94 \\
\hline & $\begin{array}{l}\text { Desviación } \\
\text { típica }\end{array}$ & 1,93 & 1,84 & 1,75 \\
\hline & Mínimo & 4,0 & 4,0 & 4,0 \\
\hline & Máximo & 10,0 & 10,0 & 10,0 \\
\hline & Mediana & 8,00 & 8,00 & 10,00 \\
\hline
\end{tabular}

Tabla 8. Nota media, DT, mínima, máxima y mediana de los test de conocimientos pre y post intervención

En el Grupo A, la nota aumentaba con las TIC 2 puntos, mientras que con la metodología tradicional el aumento fue de 4,42 puntos. Sin embargo, en el Grupo B, sucedió lo contrario: con las TIC aumenta más, concretamente, 3,77 puntos; $y$, con la tradicional, 2,47 puntos. Una de las explicaciones podría ser que en los dos grupos la mejora fue mayor cuando se explicaba el Tema 7, independientemente de la metodología empleada con el mismo: las enfermedades de transmisión sexual resultaron más motivadoras para el alumnado que las fases de la reproducción, de tipo más conceptual.

En cuanto a la fiabilidad de las rúbricas de evaluación empleadas, se utilizó el índice de fiabilidad (alfa de Cronbach) para las nueve rúbricas del Tema 5, antes de impartirse, y fue $\alpha=0,71$, lo que puede considerarse moderadamente alto. La Tabla 9 muestra los valores si se elimina cada ítem:

\begin{tabular}{lllcc} 
Medida & \multicolumn{2}{l}{ Varianza } & Correlación & Alfa de \\
de la & de $\quad$ la & elemento- & Cronbach \\
escala si & escala si & total & si se \\
se & se elimina & corregida & elimina el \\
\hline
\end{tabular}




\begin{tabular}{lllll}
\hline & $\begin{array}{l}\text { elimina } \\
\text { el } \\
\text { elemento }\end{array}$ & $\begin{array}{l}\text { el } \\
\text { elemento }\end{array}$ & elemento \\
\hline R1A & 24,56 & 22,618 & 0,527 & 0,660 \\
R2A & 24,09 & 23,840 & 0,436 & 0,678 \\
R3A & 25,21 & 20,835 & 0,539 & 0,651 \\
R4A & 25,68 & 19,498 & 0,688 & 0,615 \\
R5A & 25,38 & 20,365 & 0,691 & 0,621 \\
R6A & 27,03 & 26,817 & 0,075 & 0,735 \\
R7A & 25,26 & 26,685 & 0,075 & 0,735 \\
R8A & 24,26 & 23,170 & 0,424 & 0,677 \\
R9A & 25,82 & 26,574 & 0,090 & 0,734 \\
\hline
\end{tabular}

Tabla 9. Validez interna de los ítems de la escala de evaluación por rúbricas del Tema 5

La consistencia interna del test aumenta por encima de 0,73 cuando se excluyen las cuestiones 6, 7 ó 9. Estaríamos ante las rúbricas más independientes del resto.

El índice de fiabilidad (alfa de Cronbach) para las nueve rúbricas del Tema 7, antes de impartirse es $\alpha=0,781$ : es decir, moderadamente alto. La Tabla 10 presenta los valores si se eliminasen cada uno de los ítems:

\begin{tabular}{lllll}
\hline Medida & $\begin{array}{l}\text { Varianza de } \\
\text { de la } \\
\text { escala si } \\
\text { se }\end{array}$ & $\begin{array}{l}\text { la escala si } \\
\text { se elimina } \\
\text { el elemento }\end{array}$ & $\begin{array}{c}\text { Correlación } \\
\text { elemento- } \\
\text { total } \\
\text { corregida }\end{array}$ & $\begin{array}{c}\text { Alfa de } \\
\text { Cronbach } \\
\text { si se }\end{array}$ \\
el & & & $\begin{array}{c}\text { elimina el } \\
\text { elemento }\end{array}$ \\
elemento & & & \\
\hline R1A & 20,41 & 32,007 & 0,418 & 0,690 \\
R2A & 20,76 & 30,004 & 0,546 & 0,667 \\
R3A & 20,32 & 31,013 & 0,307 & 0,712 \\
R4A & 20,94 & 27,451 & 0,607 & 0,647 \\
R5A & 21,35 & 34,841 & 0,98 & 0,747 \\
R6A & 20,59 & 28,795 & 0,513 & 0,668 \\
R7A & 21,35 & 32,660 & 0,354 & 0,707 \\
R8A & 21,47 & 31,590 & 0,321 & 0,707 \\
R9A & 22,21 & 32,168 & 0,460 & 0,685 \\
\hline
\end{tabular}

Tabla 10. Validez interna de los ítems de la escala de evaluación por rúbricas del Tema 7

La fiabilidad alcanzó su valor máximo al eliminar la pregunta 5 (hasta $\alpha=0,747$ ).

Si se atiende a la variable "Rúbricas de evaluación", los efectos de los factores "Método" y "Tiempo" en la nota de las rúbricas, considerando la variable "Rúbrica" como la media de las nueve valoraciones del alumnado por "Método" y "Tiempo", se obtienen los siguientes resultados. El Gráfico 4 muestra la media y la DT de la nota obtenida en cada método pre y post intervención: 


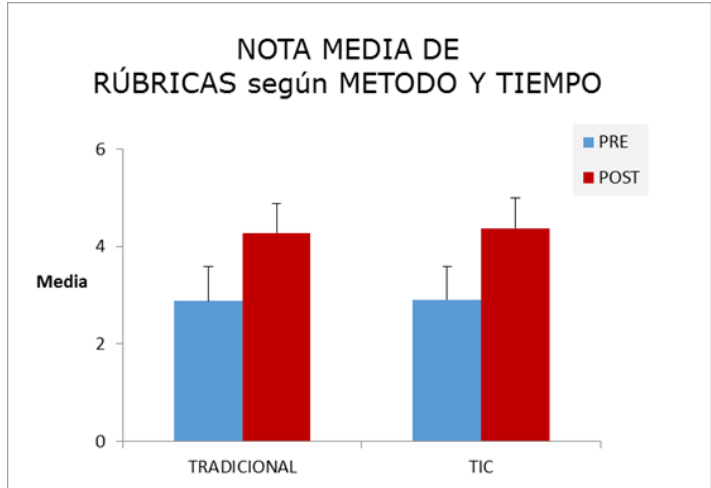

Gráfico 4. Nota media de las rúbricas de evaluación pre y post intervención mediante las dos metodologías

Con los dos métodos utilizados, la nota media de las rúbricas aumenta con el tiempo, manteniéndose aproximadamente al mismo nivel en cada momento. No podría decirse que haya un método que aumente de forma superior al otro.

Contrastando los efectos observados con el método analítico adecuado (EEG), obtuvimos los siguientes resultados:

- Diferencias significativas con el factor "Tiempo" ( $p$-valor<0,001): las valoraciones aumentaron post intervención.

- No pueden señalarse diferencias entre ambos métodos utilizados: es decir, las calificaciones obtenidas en la tradicional y en la TIC se asemejan ( $p$-valor 0,557 ) tanto al principio como al final.

- La interacción entre "Tiempo" y "Método" no fue significativa ( $p$-valor 0,785): las valoraciones obtenidas con los dos métodos evolucionaron con el mismo comportamiento en el tiempo.

Un análisis de los resultados de las rúbricas de evaluación de cada uno de los temas trabajados (en los dos grupos), permitió observar que tal y como se traduce de los resultados estadísticos comentados a lo largo de este epígrafe, los resultados de las rúbricas mejoran tras las intervenciones y de manera similar en ambos métodos y grupos (véanse Tablas 11 y 12):

\begin{tabular}{llclc}
\hline Tema 5 & $\begin{array}{l}\text { Antes } \\
\text { TIC } \\
\text { Grupo A }\end{array}$ & $\begin{array}{l}\text { Después } \\
\text { TIC } \\
\text { Grupo A }\end{array}$ & $\begin{array}{l}\text { Antes } \\
\text { tradicional } \\
\text { Grupo B }\end{array}$ & $\begin{array}{c}\text { Después } \\
\text { tradicional } \\
\text { Grupo B }\end{array}$ \\
\hline No lo sé & $17,6 \%$ & $0 \%$ & $13,1 \%$ & $0 \%$ \\
Vaga idea & $16,3 \%$ & $3,3 \%$ & $15,7 \%$ & $3,3 \%$ \\
Idea aproximada & $24,8 \%$ & $14,4 \%$ & $22,21 \%$ & $8,5 \%$ \\
Sé bien & $20,3 \%$ & $33,3 \%$ & $28,8 \%$ & $20,2 \%$ \\
Sé muy bien & $21 \%$ & $49 \%$ & $20,3 \%$ & $68 \%$ \\
\hline
\end{tabular}

Tabla 11. Resultados de las rúbricas de evaluación del Tema 5

\begin{tabular}{lllll} 
Tema 7 & Antes & Después & Antes & Después \\
& TIC & TIC & tradicional & tradicional \\
& Grupo A & Grupo A & Grupo B & Grupo B \\
\hline
\end{tabular}




\begin{tabular}{lcccc}
\hline No lo sé & $23,5 \%$ & $0 \%$ & $35,3 \%$ & $3,3 \%$ \\
Vaga idea & $27 \%$ & $1,3 \%$ & $16,3 \%$ & $4 \%$ \\
Idea aproximada & $18,3 \%$ & $12 \%$ & $21,5 \%$ & $17,6 \%$ \\
Sé bien & $21 \%$ & $24,2 \%$ & $17,6 \%$ & $36,6 \%$ \\
Sé muy bien & $10,4 \%$ & $63 \%$ & $9,2 \%$ & $38,5 \%$ \\
\hline
\end{tabular}

Tabla 12. Resultados de las rúbricas de evaluación del Tema 7

\section{Conclusiones}

Se procuró que el ambiente del aula fuese distendido y de confianza; de modo que, las clases fuesen actos comunicativos sobre los que, posteriormente, ejercer una crítica constructiva para corregir errores e incrementar la competencia en comunicación lingüística. Y, así, tras todo lo expuesto anteriormente, se ha llegado a las siguientes conclusiones:

1. En el proceso de enseñanza/aprendizaje de la asignatura de Biología-Geología, el libro de texto no ha perdido su validez; aunque no debe convertirse en herramienta únicaexclusiva.

2. La aplicación de las TIC mediante uso de presentaciones PowerPoint y procesos de investigación en Internet, más allá del uso del libro de texto, ha sido posible para esta asignatura y en esta etapa educativa.

3. La evaluación mediante test de conocimientos ha demostrado que la metodología empleada ha sido efectiva y ha ofrecido mejoras en el proceso de aprendizaje del alumnado implicado.

4. El empleo de rúbricas se ha demostrado fiable como instrumento de evaluación del proceso de enseñanza/aprendizaje de la asignatura de Biología-Geología de tercer curso de ESO. Ha favorecido la reflexión en el propio aprendizaje de cada estudiante.

Sintetizando, se puede considerar fundamental para el proceso educativo actual el diseño de unidades didácticas innovadoras que favorezcan un trabajo autónomo, que fomente el desarrollo y la capacidad de adaptación del alumnado. Sólo así, el alumnado pasará de objeto a sujeto de su aprendizaje.

\section{Bibliografía}

Bernabé, M. \& Azorín, J.M. (2015). La pizarra digital en la clase de Lenguaje Musical: aprendizaje armónico-analítico. Opción, 31 (3), 235-249.

Chow, T., Ko, E., Li, C. \& Zhou, C. (2012). The Systematic Development of Rubrics in Assessing Engineering Learning Outcomes. En International Conference on Teaching, Assessment and Learning for Engineering. Hong Kong (China). 
De Pablos, J. \& Marcelo, C. (2001). La teleformación como evolución de la enseñanza a distancia. En I Congreso Virtual de Educación. Palma de Mallorca, Universidad de las Islas Baleares.

Dodge, B. (1997). Building Blocks of a Webquest. Disponible en http://projects.edtech.sandi.net/satffdev/buildingblocks/p-index.htm

García Irles, M., Sempere, J.M., Marco, F. \& De la Sen, M.L. (2011). La rúbrica de evaluación como herramienta de evaluación formativa y Sumativa. En Jornadas Redes. Alicante, Universidad de Alicante.

García López, Mª.M. \& Romero, I.Ma . (2009). Influencia de las nuevas tecnologías en la evolución del aprendizaje y las actitudes matemáticas de estudiantes de secundaria. Electric Journal of Research in Educational Psychology, 17 (1), 369-396.

Paredes, V., Tarazona, B., Zamora, N. \& Gandía, J.L. (2014). Utilización de las rúbricas para la evaluación del Prácticum en el grado de Odontología en la Universitat de València. Revista de Formación e Innovación Educativa Universitaria, 7 (2), 88-94.

Piaget, J. (1985). De la lógica del niño a la lógica del adolescente. Ensayo sobre la construcción de las estructuras operatorias. Barcelona: Paidós Ibérica.

Sáiz, M.C., Carbonero, M.A. \& Román, J.M. (2012). Auto-regulación y auto-evaluación a través de rúbricas. En E. Fernández y Rueda, E. (Eds.), La educación elemento de transformación social. (pp. 1054-1063). Valladolid: AUFOP.

Santana, Ma .C. (2013). La utilización de rúbricas para la evaluación del trabajo colaborativo del alumnado en las wikis. Revista de Lingüística y Lenguas Aplicadas, 8, 120-128.

Valverde, J. \& Ciudad, A. (2014). El uso de e-rúbricas para la evaluación de competencias en estudiantes universitarios. Estudio sobre fiabilidad del instrumento. REDU. Revista de docencia Universitaria, 12 (1), 49-79.

Vera, L. (2008). La Rúbrica y la Lista de Cotejo. San Juan de Puerto Rico: Universidad Interamericana de Puerto Rico.

Villalustre, L. \& Del Moral, E. (2010). E-portafolios y rúbricas de evaluación en ruralnet. Pixel-Bit. Revista de Medios y Educación, 37, 93-105.

\section{REFERENCIA BIBLIOGRÁFICA}


Tarazona, B. y Bernabé, M. (2018). Rúbricas para evaluar la influencia de las TIC en el proceso de enseñanza/aprendizaje: estudio de caso en Educación Secundaria. Aula de Encuentro, n²1(1), pp. 85-104.

Beatriz Tarazona Álvarez Profesora Asociada del Dpto. de Odontología de la Universidad de Valencia Correo-e: beatriz.tarazona@uv.es María del Mar Bernabé Villodre Profesora Ayudante Doctora del Dpto. de Didáctica de la Expresión Musical, Plástica y Corporal de la Universidad de Valencia Correo-e: maria.mar.bernabe@uv.es 